\title{
O TUTOR DO CURSO DE LICENCIATURA EM QUÍMICA DA UFMG: REFLEXÕES A PARTIR DE SUA PERCEPÇÃO
}

\author{
(UNDERGRADUATE DEGREE COURSE TUTORS IN CHEMISTRY AT UFMG: REFLECTIONS BASED \\ ON THEIR PERCEPTIONS)
}

Ione Maria Ferreira de Oliveira

Ana Luiza de Quadros

Simone de Fátima Barbosa Tófani

Amary César Ferreira

Larissa Germana Oliveira Couto

Instituto de Ciências Exatas, Universidade Federal de Minas Gerais (Brasil)

\section{RESUMO}

No projeto de expansão e interiorização da educação superior, por meio do Ensino a Distância, está presente um ator pedagógico diretamente envolvido na formação dos estudantes: o tutor. Apesar de existirem inúmeras experiências de ensino envolvendo tutores, julgamos que o seu papel ainda não está bem definido. Diante desse contexto, desenvolvemos este estudo com o objetivo de entender o papel desse profissional no ensino de graduação a distância. Para isso, investigamos as experiências vividas pelos tutores no curso de Licenciatura em Química, modalidade a distância, sob o ponto de vista dos próprios tutores. Percebemos que as dificuldades vivenciadas são mais subjetivas e formativas do que técnicas. Para lidar com a diversidade de estudantes de $\mathrm{EaD}$ os tutores manifestam, entre outras necessidades, a de apoio didático e até mesmo de orientações advindas da psicologia.

Palavras chave: ensino a distância, tutoria, formação de professores.

\begin{abstract}
When we expand and 'interiorize' higher education by means of distance education, there is a 'pedagogical actor' that is directly involved in the training of students: the tutor. Although there are innumerable teaching experiences of tutors, we believe that their role has not been clearly defined yet (in distance education). In this context, the objective of this study is to examine the role of the professional in undergraduate distance education. For this reason, we researched the experiences of the tutors in the distance-based Chemistry undergraduate degree, especially focusing on the tutors' point of view. We discovered that the difficulties they
\end{abstract}


experienced were more subjective and training-related rather than technical. In order to deal with the diversity of distance learning students, the tutors demonstrated, among other things, the need for didactic support as well as guidance stemming from psychology.

Keywords: distance learning or distance education, tutoring, teachers' education.

Nas últimas décadas o ensino a distância vem sendo tema de discussão no cenário internacional. No Brasil tal discussão avançou a partir da criação da Universidade Aberta do Brasil, UAB, instituída pelo Decreto 5.800, de 8 de junho de 2006 (publicado no Diário Oficial da União, Brasil, de 09/06/2006), com a finalidade de expandir e interiorizar a oferta de cursos e programas de educação superior no país. Entendemos que a expansão e a interiorização da educação superior, alicerçadas pelas tecnologias de comunicação e informação, precisam ser acompanhadas de uma atenção à qualidade do ensino que é ofertado e, consequentemente, da qualidade da formação.

A UFMG foi credenciada a ofertar Educação a Distância, EaD a partir da Portaria nº 2.691 de 29/7/2005, publicada em 2/8/2005, no Diário Oficial da União. Em 2008 iniciou-se o curso de Licenciatura em Química, ofertado em cinco polos do interior de Minas Gerais, contando com o trabalho inicial de 17 tutores, divididos nas categorias presenciais (o7 que atendiam nos polos) e a distância (10 que atendiam na UFMG). Cada profissional atuante no curso -professor, tutor a distância, tutor presencial- tem uma atribuição distinta, mas todos estão interligados. A partir desse contexto discutiremos o papel do tutor no curso de Licenciatura em Química da UFMG.

O sujeito tutor, um ator pedagógico envolvido na formação dos estudantes e, nesse caso, na formação de professores, não tem um papel bem definido e seu perfil está, ainda, em construção. Acreditamos que a reflexão sobre o papel do tutor seja necessária uma vez que esse agente atua diretamente na metodologia e didática do curso, e também na formação dos estudantes que se aventuram em um curso a distância.

Neste estudo fomos buscar nos tutores do curso de Licenciatura em Química da UFMG o entendimento dos mesmos sobre o papel que assumiram nesse curso, as dificuldades com que se depararam ao longo do trabalho e, por fim, aquilo que caracteriza o próprio trabalho. Acreditamos que eles têm uma contribuição a dar, não só com a formação dos estudantes, mas com a construção de um modelo de 
tutoria que venha a atender as necessidades de melhoria da qualidade da educação como um todo.

\section{A TUTORIA COMO MEDIAÇÃO ENTRE PROFESSORES E ESTUDANTES}

Pesquisando a etimologia da palavra tutor, observamos que deriva do latim tútorem, e consta que seu uso inicial se deu no meio jurídico, referindo-se ao detentor da guarda ou tutela, ou seja, àquele que guarda, defende, ampara, protege. Segundo Houaiss (2001) a palavra tutor tem sua origem no século XIII e possui diferentes significados de acordo com a área que está sendo empregada.

Para exercer as atividades de tutoria no ensino a distância é necessário que o tutor tenha formação específica, uma vez que serão exigidas dele algumas funções semelhantes às de um professor: boa comunicação, liderança, dinamismo, iniciativa, entusiasmo, criatividade, capacidade para trabalhar em equipe, capacidade para gerenciar informações, habilidades pedagógicas e tecnológicas, bem como conhecimentos específicos, didáticos e metodológicos (Morais et al., 2009). Ademais, o tutor deve saber diferenciar e sequenciar as diversas informações que compartilha no ambiente de aprendizagem presencial ou a distância.

Conforme Martins (2003, p. 159):

"No sistema de EAD, o tutor tem um papel fundamental, pois é por intermédio dele que se garante a inter-relação personalizada e contínua do aluno no sistema e se viabiliza a articulação necessária entre os elementos do processo e a consecução dos objetivos propostos [...]. Como mediador neste processo, o professor tutor assume papel relevante, atuando como intérprete do curso junto ao aluno, esclarecendo suas dúvidas, estimulando-o a prosseguir e ao mesmo tempo participando do processo de avaliação da aprendizagem".

Arredondo (2003), em suas pesquisas, afirma que três características são fundamentais para um tutor de EaD: a orientação ao aluno na utilização de diferentes materiais didáticos, meios e recursos possíveis; o auxílio ao aluno para que esse supere dificuldades referentes à compreensão do conteúdo e aos estudos; e, a motivação para que o aluno mantenha a autoestima em diversas situações.

Barros Leal (2007, p. 3) corrobora com as ideias de Arredondo, ao afirmar:

"O papel do tutor ultrapassa a visão puramente técnica, transcende a exacerbação da especialidade, adquirindo competência para instrumentalizar a tecnologia. O papel do Tutor, sobremodo, supera assim o conceito reducionista de propostas estritamente 
técnicas. O Tutor é um educador a distância.[...]. Enfim, um professor no espaço virtual, exercendo a sua função de formar o aluno".

Martínez (2004) argumenta que o tutor tem duas funções principais: oferecer um feedback adequado aos estudantes e gerenciar pessoas e as relações que ocorrem entre elas. Para ele, ao tutor não cabe a tarefa de se especializar na área de conhecimento para a qual o estudante é formado e sim auxiliar no desenvolvimento de habilidades sociais e relações interpessoais, tanto presencialmente quanto a distância.

Ehuletche e Stefano (2011) observaram os fóruns de algumas disciplinas de curso a distância na Argentina, analisando as intervenções de tutores e alunos, tanto em relação à qualidade de interação quanto às unidades comunicativas contidas nessas intervenções, com o intuito de avaliar a atuação de tutores em e-learning, no que consideraram ser uma primeira etapa do próprio trabalho, visando definir as competências do tutor no ensino on-line. As autoras afirmam que o tutor deve ter competências que o habilite a auxiliar pedagogicamente os estudantes. Com isso, é função do tutor promover a permanência dos alunos no curso, aumentando a satisfação e aprendizagem dos mesmos. Também deve ter habilidade no manejo tecnológico, para transpor quaisquer imprevistos que venham a ocorrer durante o curso.

Bicalho e Barbado (2011) realizaram observações e entrevistas semi-estruturadas com três tutoras com o intuito de investigar a compreensão das mesmas sobre o papel que desempenham na construção coletiva do conhecimento em EaD. Os resultados encontrados pelas pesquisadoras indicam a necessidade de maior coerência entre os sentidos construídos e as práticas empreendidas pelas tutoras nos fóruns de discussão, consideradas as perspectivas pedagógicas da UAB. Elas ressaltam, ainda, que:

"A função do tutor e as práticas pedagógicas empregadas por ele devem ser pauta constante de reflexão e questionamentos, visando melhores resultados no âmbito do modelo de EaD que representam" (Bicalho e Barbado, 2011, p. 132).

Barros e Reis (2009, p. 59) discutem as atribuições e competências necessárias para o exercício da função tutorial. Para isso realizaram um estudo a partir de um trabalho em desenvolvimento, que envolvia a formação continuada de professores. Com ele, as autoras listam uma série de competências e habilidades necessárias ao tutor e, por isso, afirmam que "as competências e habilidades da ação tutorial são amplas e transitam entre as habilidades pessoais, as técnicas e as pedagógicas". 
Além dos trabalhos citados, outros estudos importantes sobre o papel do tutor (Martín et al., 2003; Floris e Guidi, 2010; Garbante, 2010) têm sido desenvolvidos. Sabemos que, se por um lado, o papel do tutor se assemelha ao do professor, por lidar com os estudantes de EaD, por gerenciar uma turma de alunos, por mobilizar conhecimentos didático-pedagógicos e de conteúdo, por outro lado ele lida, muitas vezes, com um conjunto mais amplo de disciplinas, o que o faz assumir uma posição mais generalista do que de especialista. Diante do cenário construído para a ação de tutoria no curso de formação de professores em Química da UFMG, na modalidade a distância, vamos dirigir o nosso olhar para essa forma de ensino no Brasil.

\section{A EAD NO BRASIL}

De acordo com Moran (2002), EaD é um processo de ensino-aprendizagem mediado por tecnologias, no qual professores e alunos estão separados espacial e/ ou temporalmente. Esse autor considera importante conhecer a diferença entre as expressões: "ensino a distância" e "educação a distância". A ênfase na primeira é dada ao papel do professor, como alguém que ensina a distância, e na segunda é ao processo como um todo.

No começo do século passado, professores e alunos de EaD estavam em diferentes espaços e tempos e a comunicação entre eles ocorria por meio de correspondências (cartas enviada pelo correio), em cursos de iniciação profissional. Na década de 20, com a radiodifusão, teve início o Programa Roquette Pinto, da Rádio Sociedade do Rio de Janeiro, sendo esse o marco inicial da ampliação dessa modalidade de educação. Nos anos 60, com a utilização de material impresso e/ou rádio e televisão, aumentavam as possibilidades de comunicação para a auto-aprendizagem. Nessa época encontram-se registros da criação de um Programa Nacional de Teleducação (Prontel), a quem competia coordenar e apoiar a tele-educação no Brasil. Esse órgão foi criado na estrutura do Ministério da Educação (MEC). Até então, a função de tutoria era mais técnica do que didática.

Nas décadas de 70 e 80 surgiram os supletivos a distância, conhecidos como telecursos, com aulas pela televisão complementadas com materiais impressos. Essa nova metodologia proporcionou formação a milhares de brasileiros. Os principais programas que prepararam esses milhares de alunos foram o Telecurso $2^{\circ}$ grau e o Supletivo $1^{\mathrm{o}}$ grau, ambos da Fundação Roberto Marinho. Esses cursos a distância ainda contavam com os recursos de áudio, videocassete, videotexto e videodisco. No final da década de 70 o computador passou a ser mais um recurso disponível para a comunicação em EaD. Nessa fase podemos observar que, no Brasil, o tutor 
continuava a ser meramente um técnico para quem a formação específica não era necessária.

Ainda na década de 70 várias políticas educacionais utilizando $\mathrm{EaD}$ foram desenvolvidas. Ações como a desenvolvida pelo Centro Federal de Educação Tecnológica (CEFET) do Rio de Janeiro junto à Secretaria de Educação Média e Tecnológica do MEC, ofertando um curso de especialização didática aplicada à educação tecnológica, foram marcantes. Esse curso de formação continuada para professores do ensino fundamental teve como objetivo a atualização desses profissionais (Saraiva, 1996). Somente a partir da década de 8o, pesquisas sobre o tema tutoria educacional começaram a discutir o papel do tutor.

A década de 90 foi muito importante para a educação brasileira, e principalmente para a EaD. Saraiva (1996) lista uma série de ações propostas pelo MEC e do Ministério das Comunicações (MC), como medidas visando a formulação de uma política nacional de EaD. A principal delas foi a chamada "Um salto para o futuro", com a criação, em cada unidade federada, de uma Coordenadoria de Educação a Distância vinculada à respectiva Secretaria Estadual de Educação. Vale ressaltar a multiplicação de congressos, seminários e encontros sobre EaD nessa década (Moran, 2002 e 2007).

Com o compromisso do governo de ampliar o atendimento educacional nos vários níveis de ensino brasileiro, a $\mathrm{EaD}$ ganha novas proporções, sendo vista como boa possibilidade de jovens e adultos terem acesso à educação, mesmo estando situados em regiões distantes dos grandes centros, onde não há universidades ou essas são poucas e insuficientes para a demanda. Esse compromisso se consolidou a partir da promulgação da Lei de Diretrizes e Bases da Educação Nacional (LDB), Lei no 9.394 de 20/12/96. O fim da década de 90 se destaca pelo grande avanço tecnológico em EaD, e pelas polêmicas em torno da qualidade do ensino ofertado e da função de cada um de seus agentes, entre eles o tutor.

Apesar dos avanços nas tecnologias de informação e comunicação (TIC) é importante notar que ainda temos um grande número de pessoas sem acesso a esses recursos, o que reforça a constatação de que a educação a distância não é um processo simples e tão democrático quanto se esperava. Nessa década é que o tutor começa a ter uma função traçada, mas o seu papel na formação do aluno ainda é foco de debate. 
Sabe-se que o tutor deve conhecer o projeto político-pedagógico do curso, bem como a estrutura e o funcionamento da plataforma educacional; participar e auxiliar no desenvolvimento do plano de orientação das atividades presenciais do curso; organizar uma base de apoio ao desenvolvimento das atividades curriculares centrada no processo de solução de dúvidas e dificuldades e na articulação de processos de comunicação e informação; manter contato virtual diário com o polo; manter boa comunicação com os professores, informando-os sobre as demandas e necessidades; construir um sistema de mediação entre a coordenação de curso, os professores, os demais tutores e os alunos objetivando a busca de soluções; participar de reuniões presenciais e/ou virtuais promovidas pela coordenação de curso, para conhecimento das atividades a serem inseridas na plataforma e nas orientações dadas aos alunos; conhecer e orientar os planos de atividades de aprendizagem dos alunos; acompanhar e monitorar o percurso pessoal de aprendizagem dos alunos, solucionando dúvidas e propondo encaminhamentos que favoreçam o progresso de todos; prestar atendimento contínuo aos alunos e incentivar o trabalho cooperativo entre os alunos do polo. Diante de tantas tarefas, parece lógica a necessidade de capacitação que os prepare para assumir as funções para as quais foram designados. E nesse contexto emerge uma questão: como capacitar para todas essas funções?

Como consequência da política de incentivo do governo brasileiro, cresce em todo país o número de consórcios de universidades públicas que investem na formação de alunos a distância. Este é o caso do Centro de Educação Superior a Distância do Estado do Rio de Janeiro (CEDERJ), um consórcio formado pelas seis universidades públicas do Estado do Rio de Janeiro, cuja preocupação inicial é oferecer cursos de graduação a distância utilizando recursos como a internet e as videoconferências. Em 2000 foi criada a Universidade Virtual Pública do Brasil (Unirede), um consórcio de instituições públicas de ensino superior, e em 2005 a Universidade Aberta do Brasil (UAB), com o objetivo de ampliar e interiorizar a oferta de cursos e programas de educação superior, por meio da educação a distância, ambas com participação da UFMG.

O primeiro edital do sistema UAB, publicado em dezembro de 2005 e conhecido como UAB1, recebeu propostas apresentadas por instituições federais de ensino superior. Para esse novo modelo de EaD, municípios e estados também apresentaram propostas de polos de apoio presencial. Em outubro de 2006, o segundo edital denominado UAB2, permitiu a participação de todas as instituições públicas, inclusive as estaduais e municipais. A partir desses editais e dos que os sucederam, inúmeras instituições passaram a ofertar cursos na modalidade a distância. 


\section{O CURSO DE LICENCIATURA EM QUÍMICA DA UFMG E O PAPEL DO TUTOR}

Em 2008 iniciaram-se as primeiras turmas de Licenciatura em Química na modalidade a distância da UFMG. Apesar de vários cursos de preparação de professores e tutores, de longas discussões em torno do funcionamento e do preparo prévio do material didático, muitos foram os problemas vivenciados. A organização inicial contou, como suporte, com algumas ações importantes já desenvolvidas no âmbito da UFMG até aquele momento.

Uma das primeiras experiências da UFMG nessa modalidade foi a participação nos projetos Programa Nacional de Tecnologia Educacional I e II (Proinfo I e Proinfo II), criado em 1997. Esses programas, de iniciativa do governo federal, foram implantados em vários estados do Brasil através das secretarias estaduais de educação, com o objetivo de promover o uso pedagógico de Tecnologias de Informação e Comunicação na rede pública de ensino. Paiva (1999) destaca outras iniciativas que foram tomadas antes do Proinfo, porém observamos que o termo tutor só passou a ser utilizado a partir do Proinfo I e II (ver portal.mec.gov.br, ProInfo).

Em 1996 também teve início o projeto "Educação a Distância: Interlocução mediada pela Tecnologia”, envolvendo ações de extensão e pesquisa. As atividades de pesquisa, financiadas pela Financiadora de Estudos e Projetos (FINEP), analisaram a viabilidade de três modelos de educação a distância mediados pela internet: grupos de discussão temática, grupos de produção colaborativa de material didático e cursos. Por sua vez, as atividades de extensão do projeto foram realizadas em 1997-1998, sendo financiadas pela Secretaria de Estado de Educação de Minas Gerais (SEE/MG) através de convênio entre a Fundação de Desenvolvimento da Pesquisa (Fundep) e o Centro de Ensino de Ciências e Matemática de Minas Gerais (CECIMIG/UFMG). Delas participaram cerca de 1.200 professores de ciências e matemática, pertencentes a 14 escolas da rede pública de ensino que foram interligadas ao CECIMIG.

Também se incorporaram a essas ações o "Projeto de Pesquisas sobre EAD", implementado pelo Cecimig/UFMG em cooperação com o Institute of Educational Technology of the Open University, Inglaterra, as atividades do Núcleo de Estudos Trabalho e Educação (NETE), e a Cátedra da UNESCO (Organização das Nações Unidas para a Educação, a Ciência e a Cultura) de formação docente na modalidade a distância (instalada na UFMG desde 1996). Apesar de estar presente o termo tutor em todos esses projetos, o papel desse profissional continua pouco conhecido. Em vários trabalhos publicados aparecem o professor e o monitor, esse último como um assessor do professor responsável pelas disciplinas oferecidas (UNESCO, 2008). 
No período de 2002 a 2005 a UFMG ofertou o Projeto Veredas, com o curso de graduação Normal Superior, na modalidade a distância, por meio da Faculdade de Educação (FaE), em parceria com a Secretaria de Estado da Educação de Minas Gerais. Esse curso foi destinado a professores de $1^{\mathrm{a}}$ a $4^{\mathrm{a}}$ séries do ensino fundamental, sem licenciatura plena, em exercício na rede. Em 2007, a UFMG passou a coordenar o projeto e lidera uma rede composta por 18 Instituições mineiras de Ensino Superior. Apenas nesse projeto o atual sistema de tutoria foi amplamente implantado, com tutores presenciais e a distância.

O Projeto Veredas, direcionado à formação de professores do ensino fundamental e infantil, fez com que as autoridades prestassem atenção à realidade da educação no estado de Minas Gerais/Br e com a formação de professores. Isto impulsionou a iniciativa da Universidade para a criação de novos cursos de graduação na modalidade a distância, instrumento importante de ampliação e democratização do acesso ao ensino superior, com impacto direto sobre várias regiões do estado.

Com a criação de quatro cursos de graduação a distância (Licenciatura em Química, Licenciatura em Biologia, Licenciatura em Pedagogia e Bacharelado em Geografia), impulsionados principalmente pelo projeto Universidade Aberta do Brasil (UAB), a UFMG assumiu formalmente a graduação a distância. O curso de Licenciatura em Química, iniciado em 2008, recebeu turmas de cinco polos em 2008 e 2010. Com isso, a tutoria do curso de Licenciatura em Química -assim como dos demais- é integrada pelos tutores a distância e tutores presenciais, duas categorias propostas pelo sistema UAB. Os tutores devem ter formação nas áreas de Química, Física, Matemática, ou áreas afins. Os candidatos a tutoria devem comprovar o exercício da função de professor ou ter o diploma de curso de pósgraduação (especialização, mestrado, ou doutorado). Além disso, para exercer a função de tutor, devem passar por um processo seletivo, classificatório. E finalmente, devem participar, obrigatoriamente, de cursos de capacitação, com aulas teóricas e práticas realizadas sob coordenação do Colegiado do Curso de Química. Só então são considerados aptos a trabalhar nessa função.

O primeiro problema em relação à seleção desse profissional aconteceu em um polo específico, no qual não havia professores de Química com a titulação de licenciados em Química. Isso já nos mostrou que o planejamento teria que sofrer algumas modificações antes mesmo do início do curso. O segundo ponto, objeto de investigação do presente trabalho, refere-se ao papel do tutor. Baseados na experiência da própria UFMG, nas orientações contidas no projeto UAB e na experiência de outros cursos, foi sendo construído um perfil esperado para estes 
tutores. Passados praticamente quatro anos de curso, algumas questões precisam ser revistas e, neste trabalho, vamos discutí-las considerando o ponto de vista dos próprios tutores: o que esses tutores vivenciaram ao longo do curso que os marcou de forma mais significativa?, Como esses tutores veem o estudante da EaD?, Quais as dificuldades que vivenciaram ao longo do curso?, E que sugestões têm a oferecer para a melhoria do trabalho do tutor?

\section{METODOLOGIA}

Organizamos um instrumento de coleta de dados -questionário- com questões divididas em informações gerais, informações sobre infraestrutura, informações sobre disciplinas curriculares e, finalmente, sobre o trabalho de tutoria. O questionário foi validado a partir de sua aplicação com um pequeno grupo de estudantes que atuaram voluntariamente com o curso de Licenciatura em Química na modalidade EaD. Após as devidas adequações, foi entregue a todos os tutores -tanto os que iniciaram o curso como os que substituíram os primeiros que se retiraram da atividade de tutoria-. Recebemos o retorno de 26 tutores, cujas respostas relativas à tutoria são objeto de análise neste trabalho.

Os dados encontrados nos questionários foram divididos em quatro grupos distintos, sendo estes: importância do próprio trabalho, sugestões dos tutores para melhorar a $\mathrm{EaD}$, dificuldades vivenciadas pelos alunos, e dificuldades vivenciadas pelos próprios tutores. Para cada grupo fizemos a categorização das respostas, agrupando-as por semelhança.

Antes de iniciarmos a discussão dos resultados, apresentamos uma breve caracterização dos tutores do curso de Licenciatura em Química na modalidade a distância. Para cada 25 estudantes matriculados no curso, um tutor presencial (da cidade polo) e um tutor a distância foram contratados para cada uma das disciplinas ofertadas no primeiro semestre do curso. Para os tutores a distância, além do atendimento on-line, há o deslocamento para os polos sempre que realizadas atividades presenciais. Como essas atividades acontecem aos sábados, os tutores a distância dispõe dos finais de semana para viagens, algumas delas de longa distância. Isso faz com que a tutoria a distância tenha maior rotatividade, pela dificuldade que representa esse trabalho. A tutoria a distância é exercida, normalmente, por exalunos do curso de Licenciatura em Química da UFMG e pós-graduandos.

Do grupo de tutores participantes deste trabalho, sete deles têm idade até 25 anos, doze com idade que varia entre 26 e 35 anos e outros sete com idade superior 
a 35. A formação que, inicialmente, seria de Licenciados em Química ou nas áreas afins (Matemática e Física) nem sempre pôde ser cumprida. Nesse grupo temos 13 licenciados em Química e seis licenciados em Matemática ou Física (esses atendem às disciplinas de Física e Matemática do curso). Quatro são bachareis (três em Química e um em Matemática) e três deles possuem formação em outras áreas (dois são Farmacêuticos e um é Engenheiro Agrônomo). Desses, dez cursam a pós-graduação na UFMG e dois deles já são pós-graduados.

A tutoria é uma atividade exercida mediante o pagamento de bolsas, sem vínculo empregatício. Ao perguntarmos a eles se exercem outra atividade, dezesseis afirmaram ser professores, sendo catorze de Ensino Médio e dois de Ensino Superior, e um dos investigados exerce a atividade de farmacêutico. Sobre o tempo em que estão ou estiveram na tutoria do curso de Licenciatura em Química, catorze afirmaram estar há mais de dois anos, três deles exercem a atividade num tempo que varia entre um a dois anos e nove estão na tutoria a menos de um ano.

\section{OS RESULTADOS ENCONTRADOS}

Passamos, agora, a discutir os resultados encontrados no nosso instrumento de coleta de dados. Para um melhor entendimento dos resultados, apresentamos um gráfico mostrando os dados em categorias e o percentual de tutores cujos comentários foram inseridos naquela categoria. Ressaltamos que os tutores podem ter emitido comentários diversos, que foram colocados em várias categorias. Assim, o total de respostas é maior que o total de tutores investigados.

Os dados obtidos, assim como a análise qualitativa das respostas, nos permitiu encontrar alguns subsídios importantes que caracterizam o trabalho que os tutores vêm desenvolvendo junto ao curso de Licenciatura em Química na modalidade a distância.

Dividimos esta análise em quatro grupos principais, conforme descrito a seguir.

\section{O que os tutores consideraram como importante no próprio trabalho}

Os comentários dos tutores em relação ao próprio trabalho foram agrupados por semelhança e encontram-se na Figura 1. 


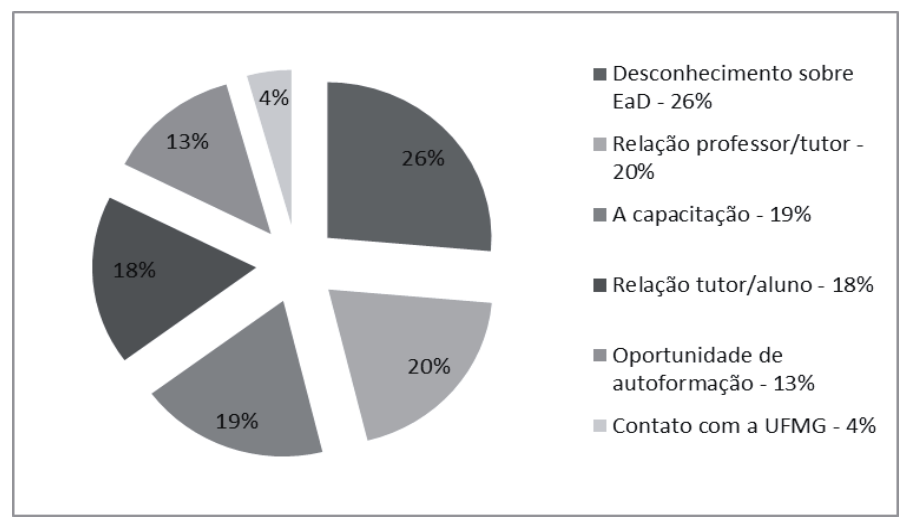

Figura 1. Gráfico sobre aspectos importantes no trabalho de tutoria

Podemos destacar, neste grupo, o relato dos tutores quanto ao desconhecimento sobre a atividade de tutoria. Para eles tratava-se de uma atividade até então desconhecida e, portanto, uma experiência nova. Sempre que as dúvidas dos alunos sobre um conteúdo específico da química eram apresentadas, os tutores afirmaram ter dificuldade em auxiliar por meio de fórum ou de chat, por exemplo. Até então só tinham vivenciado atividades presenciais e a explicação por meio das tecnologias não lhes era familiar.

O desafio de lidar com uma função na qual não tinham experiência é descrito por muitos deles como oportunidade para adquirir ou aumentar conhecimentos sobre ensinar e aprender Química. Além disso, por ser um trabalho em nível superior, os sujeitos investigados neste estudo relatam a oportunidade que a tutoria representou em inserí-los na cultura de trabalho da universidade e conviver/aprender com os professores do curso.

Para cada nova etapa do curso de Licenciatura em Química na modalidade a distância, um conjunto de atividades era preparada e desenvolvida com os tutores, em um processo de capacitação para o assessoramento aos estudantes. Essa atividade foi relatada por muitos deles como oportunidades de aprendizado, já que o papel que desempenhavam durante a capacitação não era o de alunos, mas de profissionais que iriam exercer uma atividade que se assemelhava à docência. A relação construída entre os professores formadores e os tutores durante as diversas capacitações parece ter sido positiva e, por isso, ter colaborado na elevação da autoestima dos participantes. 
Além da capacitação, a troca de experiência com professores do Ensino Superior foi citada como aspecto importante pelos tutores. Nos encontros semanais eram discutidos o desempenho dos alunos do curso $\mathrm{EaD}$ e os resultados obtidos nas atividades presenciais e a distância. O fato de participarem ativamente desses encontros e poderem fazer sugestões e críticas à dinâmica escolhida pelo professor foi considerado fundamental para a aquisição de experiência com o ensinar e o aprender.

Porém, o que mais chamou a nossa atenção foram os relatos sobre a relação construída entre os tutores e os alunos de EaD. A convivência com estudantes de cidades interioranas, que apesar de não terem a formação necessária já exercem a atividade de professor, fez com que os tutores tomassem ciência dos problemas sociais e educacionais presentes nessas regiões. Os alunos de EaD relataram aos tutores, nos encontros presenciais, as experiências e as dificuldades que enfrentam nas escolas em que atuam. A pouca leitura e a falta de expectativa de melhoria na qualidade de vida dos estudantes de cidades longínquas, aliadas ao despreparo dos professores em lidar com dificuldades de aprendizagem, faz com que a tarefa de ensinar e aprender se torne, algumas vezes, menos motivadora.

Há relatos de tutores sobre a experiência que proporcionou o contato com pessoas diferentes e com histórias de vida as mais diversas. Para os tutores que residem próximo a universidades e que têm mais oportunidade de participar de eventos culturais e científicos, conhecer a realidade de pessoas de cidades interioranas parece ter sido marcante. No curso de EaD, apesar dos cinco polos criados no interior, alguns alunos enfrentam dificuldades para chegar aos polos, tanto por residirem em cidades diferentes da cidade-polo, quanto por não terem um sistema de transporte que os permita participar com certa tranquilidade dos encontros presenciais e poder se deslocar para fazer estudos em grupos ou mesmo tirar dúvidas com os tutores locais. Conhecer o esforço que alguns estudantes dispendem para poder se manter no curso, aliado a alguns problemas de formação, parece ter sido relevante para esses tutores. Acreditamos que conhecer essa realidade também foi importante para os professores do curso.

\section{O que os tutores sugerem no trabalho de EaD}

Diante do que já foi vivenciado por cada um deles, os tutores trazem contribuições tanto para o trabalho de tutoria quanto para os cursos que funcionam na modalidade a distância. A Figura 2 mostra as categorias construídas a partir das sugestões feitas. 


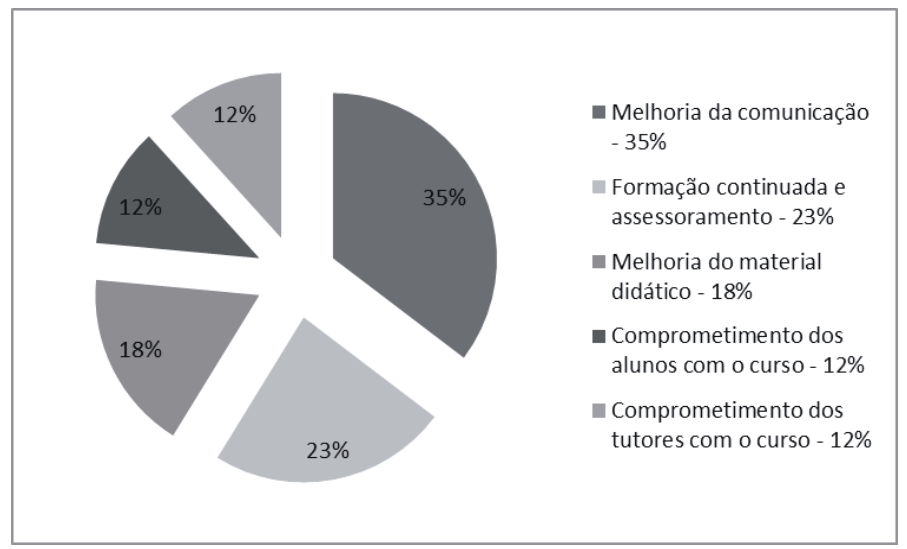

Figura 2. Gráfico com sugestões dos tutores para o curso e para a EaD

O acompanhamento dos alunos no sistema a distância parece estar representando o maior entrave ao sucesso do curso, do ponto de vista dos tutores. No entanto, essa é uma percepção construída também a partir de nossa própria experiência com o curso em questão. Os horários em que professores e tutores ficam on-line, disponíveis para discussão e tratamento dos conteúdos, não é, muitas vezes, aquele que atinge um grande número de alunos, ou porque eles não têm acesso à internet, ou porque trabalham nos horários em que a atividade é proposta, ou ainda por outros motivos. A construção de uma interação on-line mais dinâmica tem se mostrado complexa. Nesse sentido, os fóruns -ferramenta de troca de informações que ficam gravadas e disponíveis para leitura de todos os participantes- acabam por assumir esse papel, embora a resposta não seja tão imediata.

Os tutores ressaltam que a participação dos alunos nos chats, por exemplo, é importante para a formação e que estudantes, professores e tutores deveriam buscar formas de dinamizar essa participação. Os tutores também sugerem que o acompanhamento dos alunos se dê de forma mais regular, além de ressaltar a importância da busca de alternativas para a participação dos mesmos nesses chats, o que pode proporcionar um contato mais direto com o professor.

A formação e assessoramento aos tutores também aparecem como reivindicação para a melhoria do trabalho de tutoria. Para eles, o material didático referente aos cursos de preparação do tutor deveria ser ampliado e disponibilizado com mais antecedência. Os tutores presenciais, que estão mais próximos aos estudantes do curso, são mais enfáticos em relação às deficiências de formação. Eles lidam com mais 
disciplinas e, por isso, precisam navegar em um conjunto maior de conhecimentos que os permita auxiliar os estudantes. Além disso, esses tutores também não têm a assessoria direta dos professores, já que residem no polo, distante da sede do curso, onde os professores trabalham.

O pouco comprometimento dos estudantes com o curso e a necessidade tanto da melhoria do material didático das diversas disciplinas quanto de maior dedicação dos próprios tutores foram outros pontos levantados, ainda que em menor número.

\section{As dificuldades vivenciadas pelos estudantes, segundo os tutores}

Em relação aos estudantes, percebemos que os tutores foram bastante críticos e fizeram observações pertinentes quanto às dificuldades do curso, o que também faz parte das discussões entre os professores. Na Figura 3 encontram-se as categorias nas quais as dificuldades relatadas foram agrupadas.

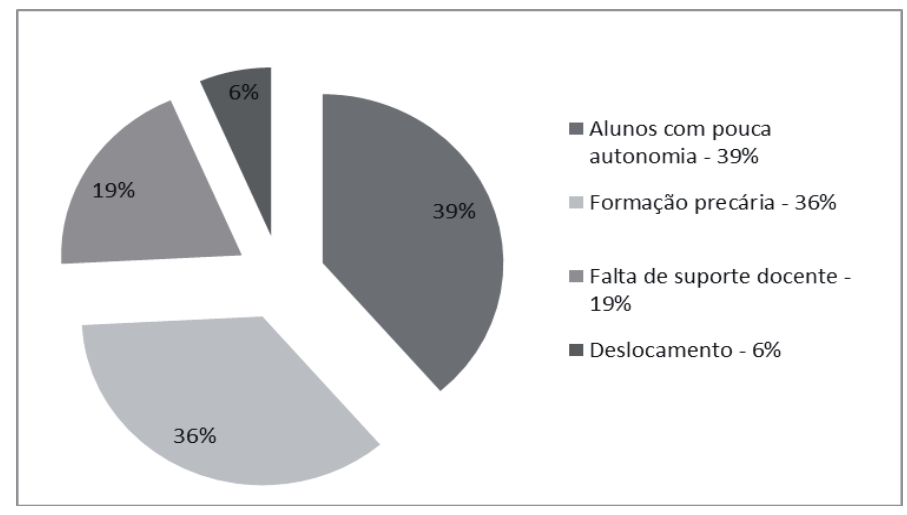

Figura 3. Gráfico das dificudades enfrentadas pelos estudantes, segundo os tutores

A questão da pouca autonomia dos estudantes aparece nas observações da maior parte dos tutores. A autonomia dos estudantes está vinculada ao controle destes sobre o planejamento, a execução e a evolução do próprio trabalho, construindo a sua aprendizagem. Para tal, são necessárias habilidades específicas que nem sempre estão presentes nesses estudantes. O desenvolvimento da autonomia exige dedicação, interesse e compromisso. Belloni (1999) argumenta que, no processo de aprendizagem autônoma, o estudante não é objeto ou produto, mas um sujeito ativo que é responsável pela própria aprendizagem e pela abstração do conhecimento para aplicação em situações diversas. Para Belloni o estudante precisa desenvolver 
as dimensões de autodireção e autodeterminação, para poder aprender sem o auxílio direto do professor.

Os estudantes do curso em questão provavelmente não estavam preparados para assumir a própria formação. Segundo os tutores, eles esperam muito dos encontros presenciais e deixam para entregar as tarefas -e provavelmente para realizá-lasquando o prazo está por findar. Os encontros presenciais são realizados aos sábados, em todos os polos. Como o curso de química tem disciplinas práticas, realizadas em laboratório, essas ocorrem nos encontros presenciais. Os demais horários do sábado são divididos por disciplinas, para que os estudantes levem suas dúvidas para serem discutidas. Segundo os tutores, os estudantes esperam do tutor uma aula sobre os conteúdos, fazendo com que eles assumam a função de professores. Poucos se preparam previamente para os encontros presenciais e alguns chegam ao extremo de ir ao polo sem ter entrado em contato com as disciplinas do curso durante a semana. Portanto, assumir a própria formação tem se mostrado como um problema para os estudantes desse curso.

É marcante a cultura de aulas presenciais entre alunos de EaD. Apesar de julgarem a modalidade a distância como ótima oportunidade para cursarem a graduação, já que podem adaptar o tempo/espaço de estudo, alguns deles não são capazes de construir uma rotina que os envolva ao curso, mesmo estando em posição física de isolamento. Para estes, o encontro presencial é o tempo/espaço de estudo. $\mathrm{E}$ a experiência dos tutores -assim como dos professores e coordenadores do curso em questão- é de que essa visão precisa ser ampliada se os estudantes quiserem "sobreviver" ao curso.

Outro fator que é percebido pelos tutores como dificultador da aprendizagem dos estudantes é a formação que antecede ao ingresso no curso. Falta a alguns desses estudantes os conhecimentos básicos de Química, de matemática, e de construção e interpretação de textos. Alguns trabalhos são entregues com cópias grosseiras e não interpretadas, geralmente oriundas da internet. Ao elaborarem um texto, mesmo que simples, há dificuldade na articulação de ideias. Quando isso é associado à pouca dedicação ao curso, o resultado é sempre desastroso.

Também para esses casos os tutores citam a falta de suporte dos docentes e o uso de uma linguagem muito especializada como fatores que desmotivam os estudantes. 


\section{As dificuldades vivenciadas pelos tutores}

Como ja dissemos, os tutores do curso em questão estão divididos entre presenciais -que residem próximos ao polo- e tutores a distância que desenvolvem suas atividades na sede da instituição e viajam aos polos periodicamente. Os dados relativos às dificuldades relatadas encontram-se na Figura 4.

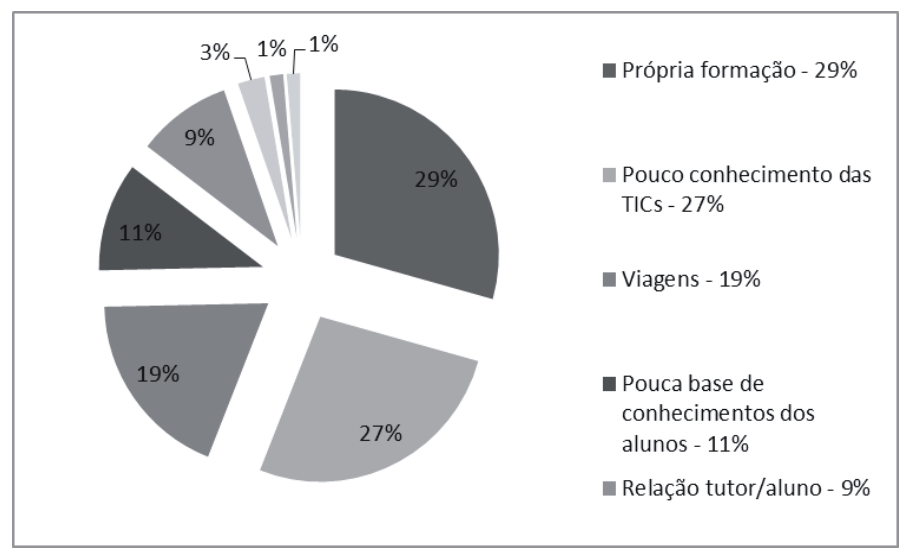

Figura 4. Gráfico das dificuldades vivenciadas pelos tutores

Como podemos perceber a própria formação foi citada como fator de dificuldade para o trabalho de tutoria. Isso se deve ao fato de lidarem com diversas disciplinas, mas também, pelo fato de não estarem preparados para lidar com o aluno a distância e com as relações que se constroem nesse trabalho. Um dos tutores afirma que a inexperiência com a atividade docente -representada por uma certa timidez diante de uma classe ou por insegurança- foi limitador para que desenvolvesse adequadamente sua atividade. Concordamos com Ehuletche e Stefano (2011) quando afirmam que o tutor deve ter competências que o habilite a auxiliar pedagogicamente os estudantes. Mas percebemos que os tutores investigados nesse trabalho sentem-se inseguros nessa tarefa.

O contato limitado com as tecnologias de comunicação e informação também foi citado como limitador. A página on-line de cada uma das disciplinas é construída no sistema da UFMG, usando o programa Moodle. O tutor afirma que não se sentia seguro em lidar com a tecnologia para intervir na página quando necessário. Vários outros citaram a dificuldade em construir explicações em um ambiente não tão familiar. 
$\mathrm{Na}$ análise desse quesito, temos algumas observações que são específicas para cada tipo de tutoria: Para os tutores a distância, as viagens representam uma delas. O tutor a distância se dirige aos polos no mínimo duas vezes ao mês, intercalando a viagem de 10 tutores para 5 polos. A distância entre os polos e a sede faz com que viajem um dia antes e retornem um dia depois do encontro presencial ou viajem à noite, tanto na ida quanto na volta. A possibilidade de acontecerem imprevistos não pode ser descartada. Por exemplo, já houve assalto a um dos ônibus no qual um tutor viajava e já aconteceu também um acidente de trânsito envolvendo um desses ônibus. Apesar de em ambos os casos o tutor envolvido não ter sofrido danos físicos, sempre fica a apreensão em relação à viagem. Além disso, há o tempo dispendido para o deslocamento que é maior do que o tempo gasto com as atividades presenciais.

Alguns tutores que já atuaram no curso e hoje não desenvolvem mais essa atividade, citam a necessidade de realizar essas viagens como fator decisivo para que abandonassem a tutoria. No entanto, para os estudantes, os encontros presenciais representam muito.

A construção de relação afetiva com os estudantes também foi citada como dificuldade. Não é papel dos tutores atuarem como professores, além de não terem formação para tal atuação. No entanto, junto aos estudantes, o papel que exercem de fato é semelhante ao do professor, tirando dúvidas, explicando determinado conteúdo, auxiliando nas tarefas, incentivando, dentre outras atividades. Para isso, eles precisam conquistar a confiança dos estudantes. E, algumas vezes, eles próprios perceberam que essa relação não estava construída, o que lhes fez aumentar a insegurança.

Outros fatores relacionados à falta de base dos estudantes, ao pouco envolvimento de alguns professores e sobre o material didático foram citados como dificuldades enfrentadas por eles.

\section{O QUE OS DADOS NOS DIZEM?}

Após quatro anos de oferta de disciplinas para o curso de Licenciatura em Química na modalidade de ensino a distância da UFMG, sabemos que o tutor tem um papel importante e podemos afirmar, inclusive, que esse papel é primordial para o bom andamento do curso.

Tanto professores quanto tutores concordam que falta apoio técnico para realização de aulas on-line, de forma a torná-las mais agradáveis do ponto de vista 
visual e didático. No entanto, para os tutores investigados neste estudo, notamos que lhes falta um certo apoio didático e/ou psicológico para lidar com os estudantes. São eles que entram em contato mais direto com os estudantes e com os professores, no processo mediativo. Portanto, as relações pessoais, sem o uso das ferramentas de comunicação, acontecem por meio deles. Lidar com o público, seja ele leigo ou especializado, exige um certo discernimento. Os tutores relataram inseguranças diante das tecnologias e na lida com os estudantes ao iniciarem o trabalho de tutoria.

Nas atividades de capacitação desses tutores sempre houve uma atenção especial para com o conteúdo das disciplinas, com o intuito de prepará-los adequadamente para as atividades do semestre. Porém eles se descreveram incapazes de motivar os estudantes de $\mathrm{EaD}$ e de lidar com o comportamento de muitos deles. Isso se deve, principalmente, ao fato de que muitos alunos de $\mathrm{EaD}$ são mais velhos que os tutores, o que os intimida um pouco.

O material de cada disciplina é disponibilizado aos alunos no início do semestre. Para os tutores que residem próximos aos polos e que sempre estão nos encontros presenciais, talvez fosse necessário uma preparação antecipada. A plataforma da disciplina on-line é disponibilizada a eles no mesmo momento em que é disponibilizada aos alunos. E, ao se depararem com algo novo, não sabem como lidar com isso. Por meio desse estudo, percebemos que é necessário mais do que a preparação em termos de conteúdo.

Porém, ao nos depararmos com a formação precária dos recém-ingressados no curso, percebemos que o tutor precisou mobilizar, também, os saberes de conteúdo. Na educação superior presencial temos percebido dificuldades conceituais básicas nos estudantes, que dificultam o entendimento dos conteúdos mais aprofundados. E se essa pouca aprendizagem é oriunda da Educação Básica, a responsabilidade da universidade também está presente, pois forma professores para a educação básica. Porém, nos polos de EaD em que temos ofertado o curso de Licenciatura em Química a distância esse problema se multiplica. Alguns dos estudantes que ingressaram no curso passaram por professores sem formação específica, tiveram pouco acesso a livros e praticamente nenhum acesso a internet durante a educação básica. Esse conjunto de fatores pode estar levando a dificuldades conceituais maiores, quando comparados aos alunos dos cursos presenciais.

Sabemos que é urgente a formação de bons professores e nisso a EaD cumpre um papel crucial. Mas essa formação em EaD só tem sentido se for acompanhada de ações junto às escolas no intuito de melhorar a educação como um todo e não 
apenas em ações pontuais. Não basta a boa vontade dos tutores e professores, ao se deslocarem ao interior do estado para oferecer um curso de graduação a quem se encontra distante dos grandes centros urbanos. O problema da educação no Brasil vai além da oferta de cursos. As aptidões com cálculos básicos e com a interpretação de textos precisam ser melhor desenvolvidas. E quem será responsável por promover o desenvolvimento dessas aptidões?, São os professores e tutores de Química, dando preferência para essa formação básica em detrimento da formação do professor de Química? Não temos essa resposta, mas julgamos que essa discussão se faz imprescindível, tanto entre a comunidade envolvida nesse curso como junto aos órgãos de fomento a essa formação.

A realidade encontrada no interior do estado de Minas Gerais/Br foi bem mais "cruel" do que esperávamos. A população interiorana parece continuar excluída, ao não ter acesso às tecnologias de informação e comunicação e nem a uma educação de qualidade. O curso de Licenciatura em Química será importante para a comunidade local, mas não será suficiente. Outras ações inclusivas devem acontecer. Nossos tutores vivenciaram situações que certamente os fizeram refletir sobre essa realidade. Acreditamos que tanto eles quanto os professores que visitaram os polos e vivenciaram um pouco dessa realidade foram transformados por ela.

\section{REFERÊNCIAS BIBLIOGRÁFICAS}

Arredondo, S. C. (2003). Formacióncapacitación del profesorado para trabajar em EAD. Educar, 21, Curitiba: Editora UFPR. (13- 27).

Barros Leal, R. (2005). A importância do tutor no processo de aprendizagem a distância. Universidade de Fortaleza (UniFor). Revista Iberoamericana de Educación, 36 (3). Espanha. [em línea] Disponível em: http://www.rieoei.org/ boletin36 3.htm (consulta 2011, 1 de diciembre).

Belloni, M. L. (1999). Educação a distância. Campinas: Autores Associados.

Bicalho, R.; Barbado, G. (2011). La función y la acción del tutor en Forum de Discusión: La palabra al tutor. Revista Iberoamericana de Educación a Distancia, 14 (1), (113-135).

Ehuletche, A. M.; Stefano, A. (2011). Evaluación de Las Competencias para la formación Tutores de E-learning. Revista Iberoamericana de Educación a Distancia, 14 (1), (75-86).

Floris, C.; Guidi, M. (2010). Curso de Ingresso Virtual para Educaciós Virtual: una estrategia dentro de la funcion tutrial de La Educación a Distancia. Revista Iberoamericana de Educación a Distancia, 13 (1), (191-208).

Garbante, G. H. (2010). La Tutoría Electrónica aplicada en los Proyectos de investigación em salud. Revista Iberoamericana de Educación a Distancia, 12 (1), (79-93).

Houaiss. (2001). Dicionário Houaiss da Língua Portuguesa. Ed. Objetiva, $1^{\mathrm{a}}$ ed. Rio de Janeiro.

Martín, X.; Padrós, M.; Puig, J. M.; Rubio, L.; Trilla, J. (2003). Tutoría: Técnicas, recursos y actividades. Madrid: Alianza. 
Martins, O. (2003). Teoria e prática tutorial e Educação a Distância. Educar, 21, Curitiba: Ed. UFPR, (153-171).

Martínez, J. (2004). El papel del tutor en el aprendizaje virtual. UOC. [em línea] Disponível em http://www.ouc.edu/ dt/20383/index.html (consulta 2012, 9 de julio).

Morais, T. M. R.; Oliveira, I. M. F.; Dalben, A. I. L. F.; Ferreira, A. C.; Toledo, M. I.; Santos, M. B. L.; Tofani, S. F. B.; Costa, T. M. L.; Carvalho, V. L. M.; Abreu, M. L. (2009). Reflexões sobre o Sistema de Tutoria e os Desafios a ele Inerentes nos Cursos a Distância da UFMG. I Congresso Internacional do Sistema $U A B$, Brasília.

Moran, J. M. (2002). O que é educação a distância. [em línea] Disponível em: www.eca.usp.br/prof/moran/dist.htm (consulta 2011, 3 de mayo).
Moran, J. M. (2007). Avaliação do Ensino Superior a Distância no Brasil. São Paulo. [em línea] Disponível em: http:// www.eca.usp.br/prof/moran/dist.htm (consulta 2011, 3 de mayo).

Paiva, V. L. M. O. (1999). O papel da educação a distância na política de ensino de línguas. In: Mendes et al. (Orgs.). Revisitações: edição comemorativa: 30 anos da Faculdade de Letras/UFMG. Belo Horizonte: UFMG/FACE. (41-57).

Saraiva, T. (1996). Educação a distância no Brasil: Lições da história. Em Aberto, 16 (70), Brasília (17-27).

UNESCO. (2008). Cátedras UNESCO no Brasil. Brasília: UNESCO. (116). [en línea] Disponível em: http://unesdoc.unesco.org/ images/0016/001603/160369por.pdf (consulta 2011, 10 de diciembre).

\section{PERFIL ACADÉMICO Y PROFESIONAL DE LOS AUTORES}

Ione Maria Ferreira de Oliveira. Doutora em Química Analítica. Professora de Química Analítica no Departamento de Química da UFMG/Brasil.

E-mail: ione@ufmg.br

Ana Luiza de Quadros. Doutora em Educação. Professora de Ensino de Química no Departamento de Química da UFMG/Brasil.

E-mail: aquadros@qui.ufmg.br

Simone de Fátima Barbosa Tofani. Doutora em Química Analítica. Professora de Química Analítica no Departamento de Química da UFMG/Brasil.

E-mail: simone@qui.ufmg.br

Amary César Ferreira. Doutor em Físico Química. Professor de Físico Química no Departamento de Química da UFMG/Brasil.

E-mail: yrra@qui.ufmg.br 
Larissa Germana Oliveira Couto. Licenciada em Química. Professora de Química no Centro Tecnológico de Minas Gerais (CETEC)/Brasil.

E-mail: lalicout@gmail.com

DIRECCIÓN DE LOS AUTORES

Departamento de Química - ICEx UFMG

Av. Pres. Antonio Carlos, 6627

Bairro Pampulha

Belo Horizonte - MG

31270-901

Brasil

Fecha de recepción del artículo: 08/01/2012

Fecha de aceptación del artículo: 14/07/2012

\section{Como citar este artículo:}

Ferreira de Oliveira, I.; de Quadros, A.; Barbosa Tófani, S.; Ferreira, A.; Oliveira Couto, L. (2013). O tutor do curso de licenciatura em química da ufmg: reflexões a partir de sua percepção. RIED. Revista Iberoamericana de Educación a Distancia, volumen $16, \mathrm{n}^{\mathrm{O}} 1$, pp. 133-154. 